\title{
ENHANCING ACTIVITY, SELECTIVITY AND STABILITY OF PALLADIUM CATALYSTS IN FORMIC ACID DECOMPOSITION: EFFECT OF SUPPORT FUNCTIONALIZATION
}

\author{
Ilaria Barlocco, ${ }^{a}$ Silvio Bellomi, ${ }^{a}$ Juan J. Delgado, ${ }^{b}$ Xiaowei Chen, ${ }^{b}$ Laura Prati, ${ }^{a}$ Nikolaos Dimitratos, ${ }^{c}$ \\ Alberto Roldan, ${ }^{d}$ Alberto Villa ${ }^{a, *}$ \\ ${ }^{a}$ Dipartimento di Chimica, Università degli Studi di Milano, via Golgi 19, I-20133Milano, Italy \\ ${ }^{\mathrm{b}}$ Departamento de Ciencia de los Materiales, Ingeniería Metalúrgica y Química Inorgánica, Facultad de \\ Ciencias, Universidad de Cádiz, Campus Río San Pedro, Puerto Real (Cádiz), E-11510, Spain \\ ${ }^{c}$ Dipartimento di Chimica Industriale e dei Materiali, ALMA MATER STUDIORUM Università di \\ Bologna, Viale Risorgimento 4, 40136 Bologna, Italy \\ ${ }^{\mathrm{d}}$ Cardiff Catalysis Institute, School of Chemistry, Cardiff University, Main Building, Park Place, CF10 3AT, \\ Cardiff, United Kingdom \\ *Corresponding author \\ E-mail addresses: Alberto.Villa@unimi.it (A. Villa)
}

\begin{abstract}
In this work, palladium nanoparticles were deposited on oxygen and phosphorous functionalised carbon nanofibers (CNFs) by sol immobilization method in order to investigate the support-metal effect on the formic acid (FA) decomposition reaction. In order to establish the presence of functional groups in the support and their effect on Pd nanoparticles, the obtained samples were then, characterised by Transmission Electron Microscopy (HR-TEM, STEM-HAADF and STEM-EDS) and X-ray photoelectron spectroscopy (XPS). FA catalytic decomposition performance, the stability and selectivity of the catalysts were evaluated in liquidphase at mild reaction conditions. The effect of the metal-support interaction in the reactivity and stability of the catalysts was demonstrated leading to superior catalytic properties in both the functionalised materials. Density functional theory (DFT) simulations provided further insights in the interaction of $\operatorname{Pd}_{15}$ cluster with different support surfaces, i.e. pristine graphene (PG), carboxyl doped graphene (G_COOH), hydroxyl doped graphene (G_OH), carbonyl doped graphene (G_CO) and phosphate doped graphene $\left(\mathrm{G}_{-} \mathrm{PO}_{3} \mathrm{H}\right)$. The cluster-support interaction strength follows the trend $\mathrm{Pd} / \mathrm{G}$ _CO > Pd/G_COOH > Pd/G_OH > $\mathrm{Pd} / \mathrm{G}_{-} \mathrm{PO}_{3} \mathrm{H}>\mathrm{Pd} / \mathrm{PG}$, confirming the increased stability of 1wt\% Pd@O-HHT and 1 wt \% Pd@P-HHT observed in the experimental results.
\end{abstract}

\section{Introduction}

Noble metals nanoparticles (NPs) are crucial for numerous vital industrial processes. Indeed, despite academia is pivoting its attention on abundant and economic transition metals, noble metal-based catalysts remain essential for the industrial sector due to their well comprehended chemistry, stability and stunning catalytic performances[1,2]. A fundamental task for the development of catalysts is to tune their properties in order to increase their catalytic selectivity, activity and durability. Among of all metal catalysts, Pd-based supported NPs are extensively employed in an wide range of heterogeneous catalytic reactions, from hydrogenations [3] to oxidations[4,5] and also in cross-coupling reactions $[6,7]$. To enhance the catalytic 
performance of Pd-based catalysts, various protocols can be adopted. Perhaps the most common is the addition of a second metal, especially $\mathrm{Au}[8]$, which can positively influence the activity and durability of $\mathrm{Pd}$ forming alloys with different proportions to tune the electronic and geometric NP's features. Another protocol is to modify the support, which can strongly affect the structure of the Pd active phase directly influencing the catalyst performance[9]. An efficient interaction between support and NPs can also prevent their migration, coalescence and Ostwald ripening, increasing the stability of the catalyst[10,11].

Carbon is an extremely attractive support material because it is not expensive, present chemical and thermal stability and it is exceptionally versatile through modification of its structure, changing the electronic and geometric properties that are fundamental in determining the catalytic performance [12-15]. Moreover, by simply burning (incineration) the carbon material or extraction, metal NPs can be easily recycled [16]. Indeed, carbon surface structural features strongly influence the metal-support interaction[17-19]. Zhao et al. reported an increase of Pd NPs binding energies in the present of surface strains in carbon nanofibers (CNFs) structure [20]. The $\mathrm{Pd}-\mathrm{C}$ interaction also strengthened in presence of vacancies with a large charge transfers from the $\mathrm{Pd} 4 \mathrm{~d}$ orbital to the $\mathrm{C}$ dangling bond [21]. Another crucial aspect to consider in order to tune the surface of the carbon materials is the introduction of heteroatoms, e.g. O, N, B and P, in its honeycomb lattice structure. NPs deposited on heteroatom-doped carbon surfaces have attracted the attention of the researchers as the NPs binding is stronger and prevents sintering problems [22]. The electronic structure of these catalysts is also affected improving their activity in reactions such as hydrodeoxygenation[23], electrocatalytic oxygen reduction[24], photocatalytic oxidation[25]. Oxygen as a dopant influences the charge transfer between carbon and metal nanoparticles, in fact, most heteroatoms enhance the electron density of the neighbouring carbon atoms increasing the back-donation from $C$ to the metal atoms [26]. Nitrogen and boron doped C-materials have received an increasing consideration as they directly affect the Fermi level of the solid[27,28], and Pd and Pd alloyed NPs supported on them showed promising activity and durability during FA decomposition reaction[29-32]. Although the deposition of Pd NPs on oxygen and phosphorous doped carbon for formic acid dehydrogenation reaction remain a challenge, Xin et al. disclosed the effect of phosphorous doping by XPS concluding that P-doping influences the electronic properties of Pd enhancing its activity and the catalysts stability [33].

The aim of the work here presented is to enhance the stability and the activity of the Pd catalyst by the introduction of oxygen and phosphorous in the structure lattice of the carbon-support. As reported by Zhang at al. the lone pair around the acidic $O$ functional groups (e.g. anhydrides and carboxylic acids) can interact with the $4 \mathrm{~d}$ and 5 s orbitals of $\mathrm{Pd}$ strengthening the metal-support interaction, anchoring the NPs and avoiding agglomeration[19]. Phosphorous was chosen because of its low electronegativity and larger size [34].

In order to investigate more deeply the electronic and structural effects, formic acid decomposition (FAD) reaction in liquid phase under mild conditions was used as a probe reaction. According to the U.S. department of Energy, FA is one of the most promising sources of clean hydrogen as it is liquid at standard temperature and pressure, and possesses a relatively high hydrogen content $\left(4.4 \mathrm{wt} \%\right.$ of $\left.\mathrm{H}_{2}\right)$ [35]. The FAD reaction takes place in two different pathways:

a) $\mathrm{HCOOH} \rightarrow \mathrm{CO}_{2}+\mathrm{H}_{2} \quad \Delta \mathrm{G}=-48.4 \mathrm{~kJ} \mathrm{~mol}^{-1}$

b) $\mathrm{HCOOH} \rightarrow \mathrm{CO}+\mathrm{H}_{2} \mathrm{O} \quad \Delta \mathrm{G}=-28.5 \mathrm{~kJ} \mathrm{~mol}^{-1}$

Reaction a) is the dehydrogenation process, the desired reaction, in which $\mathrm{H}_{2}$ is produced and $\mathrm{CO}_{2}$ can be recycled again to form FA in a closed cycle[36,37]. Pathway b) is the side-reaction, which produce carbon monoxide. CO-free decomposition of formic acid is crucial for a formic acid based energy technology[38]. In 
order to disclose the relation between catalytic behaviour and structure, fresh and used Pd supported on carbon nanotubes catalysts were characterized by transmission electron microscopy (HR-TEM, STEM-HAADF and STEM-EDS) and X-ray photoelectron spectroscopy (XPS). Moreover, to understand the interaction between the surface and the Pd NPs and to reveal the connection between functionalities and catalytic properties, we carried out a systematic investigation combining experiments and computational simulations.

\section{Experimental method}

\subsection{Materials and chemicals}

Sodium tetrachloropalladate (II) $\left(\mathrm{Na}_{2} \mathrm{PdCl}_{4}, 99.99 \%\right)$, sodium borohydride $\left(\mathrm{NaBH}_{4}, 99.99 \%\right)$ and poly(vinyl alcohol) (PVA, average molar weight 10,000, 87-89 \% hydrolysed) were used without any pre-treatment for the catalyst synthesis and they were purchased from Sigma-Aldrich (Haverhill, MA, USA). All the catalytic tests were carried out using Formic acid ( $\geq 95 \%$, Sigma-Aldrich) and deionised water ( $\geq 99 \%$, Sigma-Aldrich) as the substrate and the solvent, respectively. CNFs PR24-HHT (High Heat Treated carbon nanofiber) were obtained from Applied Science Company (Cedarville, OH, USA).

\subsection{Support functionalisation}

Phosphorous Functionalised-HHT were obtained in a two-necked $250 \mathrm{~mL}$ round-bottom flask placed in a heating system reflux condenser. $2 \mathrm{~g}$ of $\mathrm{HHT}$ were added to a $100 \mathrm{~mL}$ solution of $\mathrm{HNO}_{3}(65 \% \mathrm{wt})$ and $\mathrm{H}_{3} \mathrm{PO}_{4}$ ( $\geq 99 \% \mathrm{wt}$ ) $1: 1 \mathrm{vol} / \mathrm{vol}$ mixture. After $1 \mathrm{~h}$ at $100^{\circ} \mathrm{C}$ the solid was filtered, washed with $5 \mathrm{~L}$ of water and dried in oven at $80{ }^{\circ} \mathrm{C}$. The material was calcined at $400{ }^{\circ} \mathrm{C}$ in a tubular furnace in static air conditions for $4 \mathrm{~h}$ obtaining P-HHT.

Oxygen Functionalised-HHT (O-HHT) were obtained in the same heating system reflux condenser as Phosphorous Functionalised-HHT. $2 \mathrm{~g}$ of HHT were added to $100 \mathrm{~mL}$ of $\mathrm{HNO}_{3}(65 \% \mathrm{wt})$. After $1 \mathrm{~h}$ at $100{ }^{\circ} \mathrm{C}$ the solid was filtered, washed with $5 \mathrm{~L}$ of water and dried in oven at $80^{\circ} \mathrm{C}$.

\subsection{Catalyst preparation}

In a typical sol immobilization procedure[39], the catalyst was prepared adding the solution of the precursor salt $\left(\mathrm{K}_{2} \mathrm{PdCl}_{4}, 9.40 \times 10^{-2} \mathrm{mmol}\right.$ in $100 \mathrm{~mL}$ of $\mathrm{H}_{2} \mathrm{O}$. After, the capping agent PVA (M/PVA=1/0.5 (wt/wt)) was added. Then, a fresh aqueous solution of $\mathrm{NaBH}_{4}\left(\mathrm{M} / \mathrm{NaBH}_{4}=1 / 8 \mathrm{~mol} / \mathrm{mol}\right)$ was put to the mixture solution of $\mathrm{Pd}$ precursor and PVA at once. After 30 minutes under vigorous stirring $1 \mathrm{~g}$ of HHT nanofibers (O-HHT and PHHT) was added in order to support the metal colloidal solution. The amount of support was calculated in order to have a loading of $1 \mathrm{wt} \%$. By using sulphuric acid, the suspension was acidified to $\mathrm{pH} 2$ and stirred for $30 \mathrm{~min}$ in order to ensure the full immobilization of the nanoparticles on the support. The solid was filtered, washed with $1 \mathrm{~L}$ of $\mathrm{H}_{2} \mathrm{O}$ and dried in oven at $80^{\circ} \mathrm{C}$ for 1 day (1wt\%Pd@O-HHT and $1 \mathrm{wt} \% \mathrm{Pd@P-HHT).}$

\subsection{Catalytic tests}

Formic acid dehydrogenation: Liquid-phase formic acid decomposition was carried out in a two-necked 100 $\mathrm{mL}$ round-bottom flask placed in a water bath equipped with a magnetic stirrer and a reflux condenser.

Typically, $10 \mathrm{~mL}$ of an aqueous solution $0.5 \mathrm{M}$ of $\mathrm{HCOOH}$ was placed in the reactor and the reaction temperature was set-up at $30^{\circ} \mathrm{C}$. The Formic Acid/metal molar ratio is 2000:1 and once the solution reached the desired temperature, the solution was stirred at $1400 \mathrm{rpm}$. At these experimental conditions we have shown we operate under kinetic regime[40]. Recycle tests were performed on the catalysts using $25 \mathrm{~mL}$ of 
an aqueous solution of $\mathrm{HCOOH} 0.5 \mathrm{M}$ in a $250 \mathrm{~mL}$ round-bottom flask at the same experimental conditions of the reaction previously discussed.

Product analysis: Formic acid conversion was analysed using high-performance liquid chromatography (HPLC). In particular, a $\mathrm{H}^{+}$chromatographic column was used (Alltech OA-10,308, 300 mm_7.8 mm) with UV detector settled at $210 \mathrm{~nm}$. Liquid samples were withdrawn periodically $(200 \mu \mathrm{L})$ and diluted to $5 \mathrm{~mL}$ with $\mathrm{H}_{3} \mathrm{PO}_{4}$ solution ( $0.1 \mathrm{wt} \%$ ) which was also the eluent of the analysis. The isocratic eluent flow was set at 0.4 $\mathrm{ml} \mathrm{min}{ }^{-1}$. The gas phase was analysed by gas chromatography (Agilent, mod. 7890) equipped with a TCD detector and a proper set up for the quantification of $\mathrm{H}_{2}$ and $\mathrm{CO}$. An online micro-gas chromatograph (Agilent 3000A) was used in order to analyse the gas phase after 30 minutes of reaction. The apparatus is equipped with two different columns: (a) a molecular sieve module and (b) an OV-1 module (stationary phase of polydimethylsiloxilane), and a TCD detector. Measure of $\mathrm{CO}_{2}$ and $\mathrm{CO}$ were performed using calibration curves obtained from commercial standards.

\subsection{Catalyst characterization}

Samples were characterized by X-Ray photoelectron spectroscopy (XPS). Thermo Scientific K-alpha+ spectrometer was used for XPS measurements. The samples were analysed using a monochromatic Al X-Ray source operating at $72 \mathrm{~W}$, with the signal averaged over an oval-shape area of $600 \times 400 \mu$. Data were recorded at $150 \mathrm{eV}$ for survey scans and $40 \mathrm{eV}$ for high resolution (HR) scans with a $1 \mathrm{eV}$ and $0.1 \mathrm{eV}$ step size, respectively. CASAXPS (v2.3.17 PR1.1) was used for the analysis of the data, using Scofield sensitivity factors and energy exponent of -0.6 .

Transmission electron microscopy characterization was carried out on a double Cs aberration-corrected FEI $\operatorname{Titan}^{3}$ Themis 60-300 microscope equipped with a monochromator, a X-FEG gun and a high efficiency XEDS ChemiSTEM, which consists of a 4-windowless SDD detectors. HR-STEM images were recorded at $200 \mathrm{kV}$ and using a high-angle annular dark-field (HAADF) detector with a camera length of $11.5 \mathrm{~cm}$. This technique is the most appropriate to distinguish small nanoparticles supported on light supports because the image intensity is sensitive to the atomic number of the elements $\left(Z^{2}\right)$. XEDS mappings were performed using a beam current of $200 \mathrm{pA}$ and a dwell time per pixel of $128 \mu \mathrm{s}$. To improve the visual quality of the elemental maps obtained, these were filtered using a Gaussian blur of 0.8 using Velox software. Based on the STEM-HAADF images of the catalysts, the diameters of more than 150 metal particles randomly selected were measured and the corresponding metal particle size distributions (PSD) were determined. Based on these PSDs, the average particle diameter (d) was calculated according to the following expression: $d=\sum n_{i} d_{i} / \sum n_{i}$, where $n_{i} \geq 200$. Likewise, the total metal dispersion was calculated according to $D=N_{s} / N_{t}$, where $N_{s}$ is total number of surface metal atoms and $\mathrm{N}_{\mathrm{t}}$ is total number of atoms in the metal particle. For particle size calculation ImageJ software was used.

Surface area was determined by low temperature $\left(\mathrm{T}=-196{ }^{\circ} \mathrm{C}\right) \mathrm{N} 2$ adsorption using an Tristar II 3020 Micromeritics apparatus. Before measurement, samples were outgassed at $\mathrm{T}=150{ }^{\circ} \mathrm{C}$ for $4 \mathrm{~h}$ in a nitrogen flux. Surface area was calculated from nitrogen isotherms by B.E.T. theory using the instrumental software (Version 1.03).

\subsection{Computational method}


The Vienna ab-initio simulation package (VASP) was used to perform periodic plane-wave density functional theory (DFT) calculations in a graphene supported Pd NP model[41,42]. Spin-polarized revised Perdew-BurkeErnzerhof ( $\mathrm{rPBE}$ ) method of the generalized gradient approximation (GGA) with a plane-wave kinetic cutoff energy of $450 \mathrm{eV}$ was employed to describe the exchange-correlation [43]. The projector augmented wave (PAW) represented non-spherical contributions to the core from the valence electrons' gradient corrections.[44-46] The DFT-D3 method of Grimme with the zero damping approach[47] was utilized to include the long-range interactions. Moreover, the solvent effect of water was also calculated by an implicit polarized continuum model (PCM), which describes the interaction between a solvent and solute in planewave DFT.[48,49] The optimized convergence threshold of electronic relaxation and internal forces were set to $10^{-7} \mathrm{eV}$ and $0.01 \mathrm{eV} / \AA$, respectively. A $0.2 \AA^{-1} \mathrm{k}$-spacing mesh was used to accurately define the Brillouin zone with a smearing broadening of $0.1 \mathrm{eV}$.

A catalysts model simulating the experimental samples is prohibitively expensive to model, and a simplified model was employed. Despite it, the model includes the interface between the carbon substrate and the Pd particle. The optimized lattice parameter of the graphene layer employed as support is $2.469 \AA$, which agrees with the experimental value $(2.46 \AA$ ). [ [50] All surfaces were represented by a $p(8 \times 8)$ supercell slab model to avoid the interaction between the defects. Layered graphene is an acceptable model for the large diameter nanofibers utilised in the experiment. The extensive conformational study of the supported nanoparticle restricted its size to 15 atoms. To determine the most stable initial shape of the $\operatorname{Pd}_{15}$ cluster on pristine graphene, in addition to moieties that maximized the exposure of the most stable facets and those based on previous reports, an unbiased genetic algorithm (GA) was employed to explore almost 100 independent structures [51][52]. A $15 \AA$ of vacuum perpendicular to the slab was added to avoid any interaction with periodic images

Clusters adhesion energy $\left(\mathrm{E}_{\mathrm{ADH}}\right)$ was calculated as the difference between the combined system (cluster attached to the surface) and the isolated species (clusters and selected surface in gas phase with exactly the same geometry as the combined model). Hence, $E_{A D H}$ only accounts for the adhesion and not the reconstruction energy.

\section{Results}

Two different $\mathrm{O}$ and $\mathrm{P}$ functionalised high-heat treated carbon nanofibers (HHT-CNFs) were prepared, i.e. OHHT and P-HHT. The P functionalised non-carbonized catalyst was not prepared as previous studies of our group demonstrated that a heat treatment above $400^{\circ} \mathrm{C}$ favours the formation of direct $\mathrm{C}-\mathrm{P}$ bond instead of the more unstable C-O-P bond[53]. C-O-P bond leads to P-leaching from the carbonaceous surface, hence, decreasing the stability of the catalyst[54]. The support functionalization procedure did not affect the surface area ( $37 \pm 0.9,36 \pm 1.3$ and $36 \pm 2.1 \mathrm{~m}^{2} \mathrm{~g}^{-1}$ for HHT-CNFs, O-HHT-CNFs and P-HHT-CNFs, respectively). Several studies have reported that HHT CNFs lead to an superior activity in FAD because of the presence of smaller and homogeneously dispersed Pd nanoparticles[55,56]. The prepared HHT-CNTs were used as support for palladium nanoparticles via sol immobilization technique, using PVA as capping agent and $\mathrm{NaBH}_{4}$ as reducing agent.

\subsection{XPS results}

XPS analysis were performed to analyse oxygen and phosphorous functionalities introduced on the CNF surfaces and to determine Pd oxidation state as well as its content at the surface (Table 1, Figures S1-S2). The oxidative treatment with $\mathrm{HNO}_{3}$ increased the oxygen content from $0.9 \%$ of $\mathrm{HHT}$ to $7.77 \%$ for O-HHT. After the functionalization with a mixture of $\mathrm{H}_{3} \mathrm{PO}_{4}$ and $\mathrm{HNO}_{3}, 4.83 \%$ of $\mathrm{O}$ and $1.39 \%$ of $\mathrm{P}$ where detected on the 
surface of the carbon material. $\mathrm{Pd}$ samples showed that after $\mathrm{O}$ and $\mathrm{P}$ functionalization $\mathrm{Pd}$ exposure increased 1wt\%Pd@P-HHT (1.57\%)> 1wt\%Pd@O-HHT (1.14\%)> 1wt\%Pd@HHT (0.77\%) (Table 1)[57]. It is worth to note that P content on 1wt\%Pd@P-HHT (0.56\%) decreased compared to P-HHT (1.39\%), whereas oxygen content is similar. On the contrary, O content on 1wt\%Pd@O-HHT (6.48\%) decreased compared to O-HHT (7.77\%). As no $\mathrm{P}$ and $\mathrm{O}$ leaching was found, we can assess that $\mathrm{Pd}$ is preferentially deposited on $\mathrm{O}$ (for 1\%Pd@O-HHT) and P functionalities (1wt\%Pd@P-HHT). Table 1 summarizes the chemical species observed on the surface and their concentration. Peak assignments were made according to phosphorylated carbons[58] and to oxidize carbon nanotubes[59]. In the $01 \mathrm{~s}$ region, three main oxygen groups were identified. BE of 531.2$531.4 \mathrm{eV}$ can be assigned to a carbon-oxygen double bond and to $\mathrm{P}=\mathrm{O}$ and $\mathrm{P}-\mathrm{O}$ species, the signal around 533 $\mathrm{eV}$ to $\mathrm{C}-\mathrm{O}, \mathrm{C}-\mathrm{O}-\mathrm{C}, \mathrm{P}-\mathrm{O}-\mathrm{C}$ and the signal at $534 \mathrm{eV}$ can be assigned to carboxylic species.

Table 1: Results of $O, P$ and $P d$ high resolution (HR) spectra

\begin{tabular}{|c|c|c|c|c|c|c|c|c|}
\hline Sample & & O1S & $P 1 S$ & & $P d 3 d$ & $\begin{array}{l}\text { Atomic } \\
\text { ratio\% }\end{array}$ & & \\
\hline & & $\begin{array}{c}C=0, \\
P=O, P-O\end{array}$ & $\begin{array}{c}\mathrm{C}-\mathrm{-O}, \\
\mathrm{C}-\mathrm{O}-\mathrm{C}, \mathrm{P}- \\
\mathrm{O}-\mathrm{C}\end{array}$ & $\mathrm{COOH}$ & $\begin{array}{c}\mathrm{C}-\mathrm{O}-\mathrm{PO}_{3} \\
\mathrm{C}-\mathrm{P}\end{array}$ & $\mathrm{Pd}^{2+}$ & $\mathrm{Pd}^{0}$ & C-O-P-Pd \\
\hline $\mathrm{HHT}$ & $\begin{array}{c}\text { BE } \\
\text { Atom } \\
\%\end{array}$ & $\begin{array}{l}531.2 \\
(50.4)\end{array}$ & $\begin{array}{l}533.0 \\
(48.4)\end{array}$ & $\begin{array}{l}534.1 \\
(1.2)\end{array}$ & - & - & - & $\begin{array}{c}99.1-0.9-0- \\
0\end{array}$ \\
\hline O-HHT & $\begin{array}{c}\text { BE } \\
\text { Atom } \\
\%\end{array}$ & $\begin{array}{l}531.3 \\
(54.8)\end{array}$ & $\begin{array}{l}532.9 \\
\text { (35.3) }\end{array}$ & $\begin{array}{l}533.9 \\
(8.5)\end{array}$ & - & - & - & $\begin{array}{c}92.23- \\
7.77-0-0\end{array}$ \\
\hline P-HHT & $\begin{array}{c}\text { BE } \\
\text { Atom } \\
\%\end{array}$ & $\begin{array}{l}531.4 \\
(61.3)\end{array}$ & $\begin{array}{l}533.0 \\
(33.2)\end{array}$ & $\begin{array}{l}534.2 \\
(5.5)\end{array}$ & $\begin{array}{l}134.2 \\
(100)\end{array}$ & - & - & $\begin{array}{c}93.48- \\
4.83-1.39\end{array}$ \\
\hline 1wt\%Pd@HHT & $\begin{array}{c}\text { BE } \\
\text { Atom } \\
\%\end{array}$ & $\begin{array}{l}531.3 \\
(49.8)\end{array}$ & $\begin{array}{l}533.2 \\
(49.2)\end{array}$ & $\begin{array}{l}534.3 \\
(1.0)\end{array}$ & & $\begin{array}{l}336.4 \\
(38.5)\end{array}$ & $\begin{array}{l}335.0 \\
(61.5)\end{array}$ & $\begin{array}{c}96.51- \\
2.72-0- \\
0.77\end{array}$ \\
\hline 1wt\%Pd@O-HHT & $\begin{array}{c}\text { BE } \\
\text { Atom } \\
\%\end{array}$ & $\begin{array}{l}531.2 \\
(56.3)\end{array}$ & $\begin{array}{l}533.0 \\
(33.4)\end{array}$ & $\begin{array}{l}534.2 \\
(10.7)\end{array}$ & & $\begin{array}{l}336.8 \\
(43,5)\end{array}$ & $\begin{array}{l}335.0 \\
(56,5)\end{array}$ & $\begin{array}{c}92.11- \\
6.48-0- \\
1.14\end{array}$ \\
\hline 1wt\%Pd@P-HHT & $\mathrm{BE}$ & 531.4 & 532.8 & 534.4 & 133.9 & 336.5 & 334.8 & \\
\hline
\end{tabular}




\subsection{TEM-STEM results}

Figure 1 shows representative STEM images of the Pd catalysts in its fresh state, as well as the particle size distribution. We can observe that Pd nanoparticles are, in general, homogenously distributed on the carbon nanotube surface, although some agglomerations are observed. The average particle size decreases from 3 $\mathrm{nm}$ to $2.3 \mathrm{~nm}$ when the treated supports are used. If we consider the particle size distribution, we can observe that the 1wt\%Pd@HHT exhibits a nearly unimodal distribution centred at $3 \mathrm{~nm}$. When palladium is supported on P-HHT and O-HHT supports, the fraction of particles smaller than $2 \mathrm{~nm}$ dramatically increase and a bimodal particle size distribution is obtained. These small particles slightly increase the dispersion of the $\mathrm{Pd}$ nanoparticles from $36 \%$ up to $42 \%$.

On the other hand, the composition of the samples was analysed by acquiring STEM-EDS mappings. Figure 2 includes a statistical relevant mapping obtained for sample 1wt\%Pd@P-HHT. We clearly can observe the presence of $P$ in the carbon nanotube, although the phosphorous content in some areas is below the detection limit. The EDS spectrum of isolated particles A and B in the image, shows the fact that some particles are in intimal contact with $\mathrm{P}$, but not all of them. This can be related with the bimodal particle size distribution observed in these samples. A low magnification EDS mapping is included in the supporting information (Figure S3) to show that P can be found as well in large carbon nanotubes.
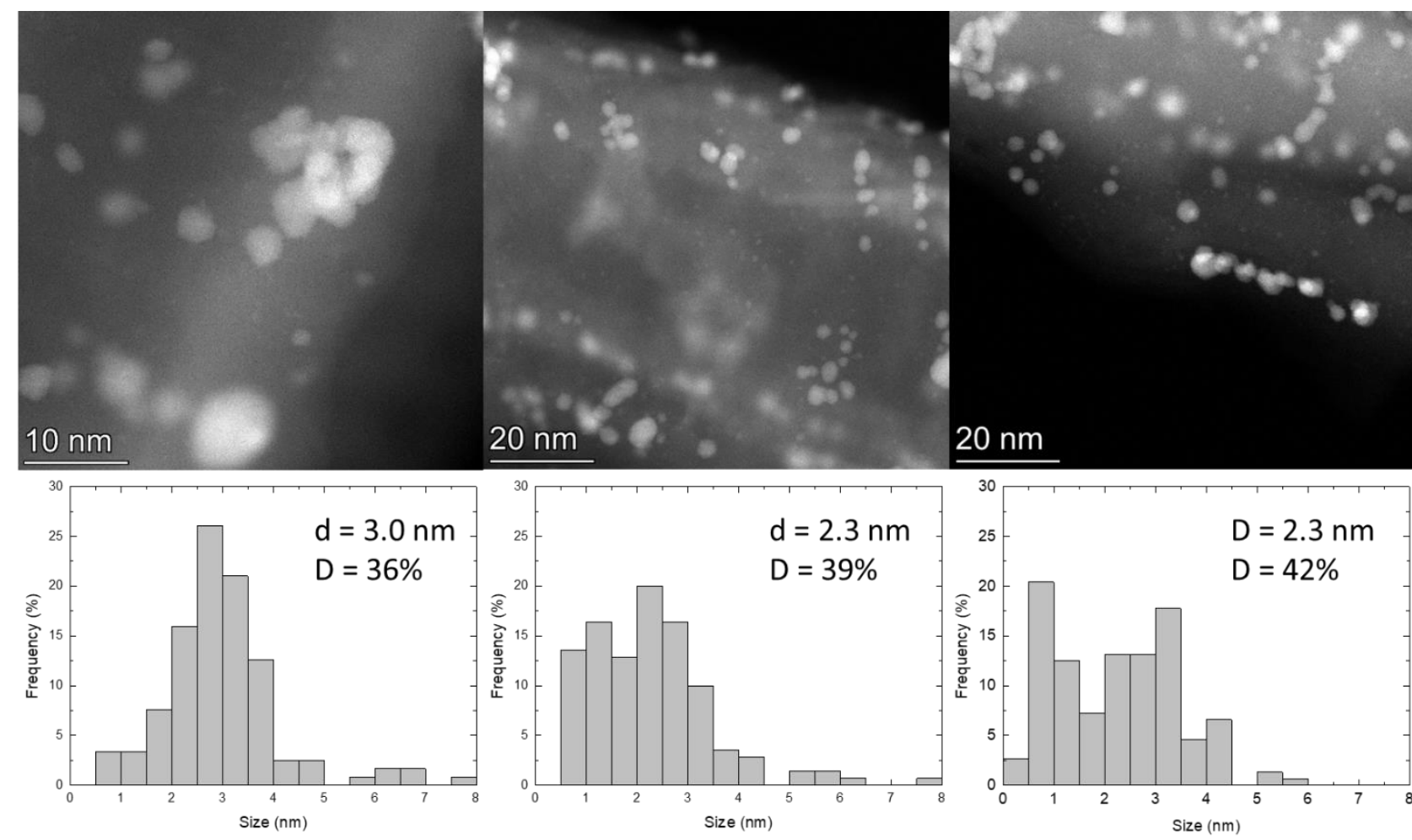
Figure 1: Representative HR-STEM images (top) and particle size distribution (bottom) of 1wt\%Pd@HHT (left) 1wt\%Pd@O-HHT (middle) and 1wt\%Pd@P-HHT (right).

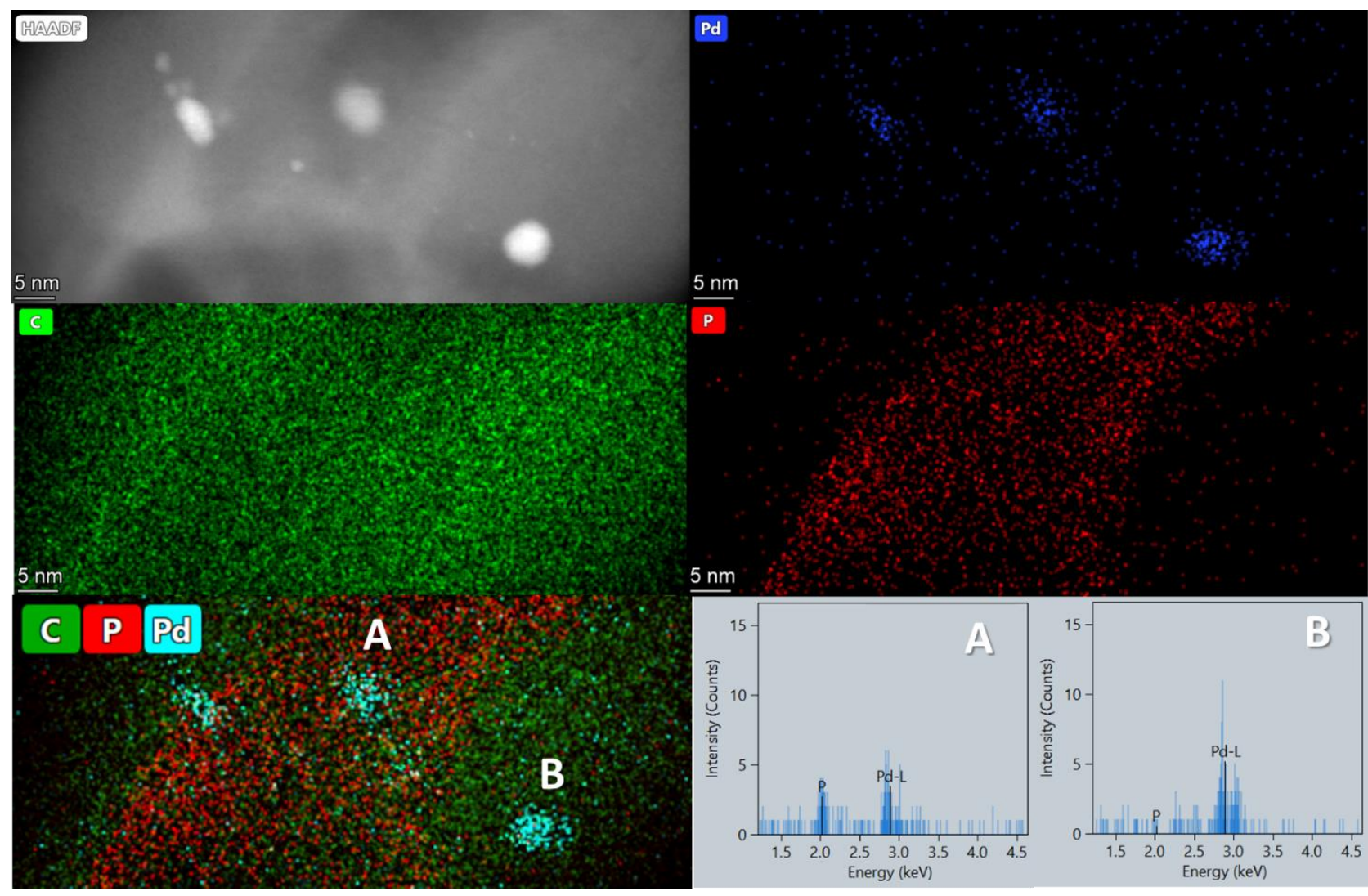

Figure 2: STEM-EDS element mapping analysis of sample 1wt\%Pd@P-HHT. EDS spectra of selected nanoparticles are also included.

\subsection{Catalytic activity}

The catalytic performance of Pd NPs deposited on the functionalised supports, i.e. 1wt\%Pd@P-HHT and 1wt\%Pd@O-HHT, was evaluated in liquid-phase formic acid decomposition and compared with 1wt\%Pd@HHT. 1wt\%Pd@O-HHT showed an activity superior to 1wt\%Pd@HHT, i.e. $1485 \mathrm{~h}^{-1}$ and $979 \mathrm{~h}^{-1}$, respectively. On the other hand, 1wt\%Pd@P-HHT exhibited a similar activity $\left(899 \mathrm{~h}^{-1}\right)$. These activity's values are comparable with the majority of the catalysts present in literature (Table S1). Kinetic profiles for the three catalysts were examined after $2 \mathrm{~h}$ of reaction (Figure 3). A similar reaction profile was obtained for both functionalised catalysts, showing also no signs of deactivation. An exceptionally high conversion (85 and 70 \%) for the two functionalised catalysts was achieved. Considering the conversion at $2 \mathrm{~h}$ of reaction and XPS and TEM analyses results it was possible to correlate the properties of the catalysts with their catalytic behaviour. The higher conversion of 1wt\%Pd@P-HHT and 1wt\%Pd@O-HHT compared 1wt\%Pd-HHT to can be attributed to the smaller Pd particles and the higher particles dispersion observed by HR-TEM in the functionalised materials (from $3.0 \mathrm{~nm}$ for the non-functionalised material to $2.3 \mathrm{~nm}$ for $1 \mathrm{wt} \% \mathrm{Pd@P-HHT}$ and 
1wt\%Pd@O-HHT). In addition, XPS showed an increase in Pd exposure for the two functionalised materials (from 0.77\% for 1wt\%Pd@HHT to 1.57\% for 1wt\%Pd@P-HHT and 1.14\% for 1wt\%Pd@O-HHT), which in turn led to an increase in the surface's active sites. The direct participation of the support in the activity of the catalysts can be excluded. The bare supports were tested in FAD reaction at the same reaction condition, but no conversion was observed.

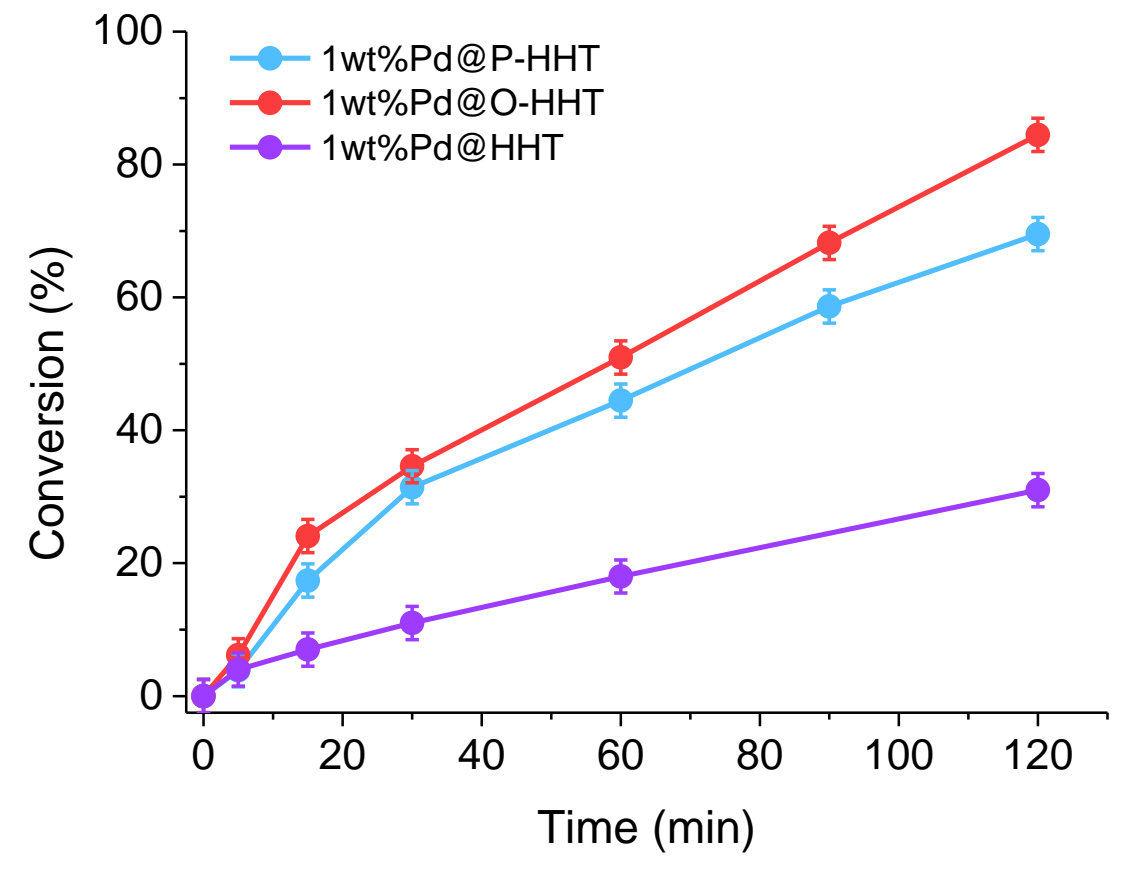

Figure 3: kinetic profile of 1wt\%Pd@P-HHT (light blue), 1wt\%Pd@O-HHT (red) and 1wt\%Pd@HHT (violet) catalysts for formic acid dehydrogenation

A crucial feature of the catalysts to be implemented at large scale is the durability of the catalyst. We performed recycling tests on the three systems after $2 \mathrm{~h}$ of reaction. Stability tests were performed by filtering the catalyst without any further purification treatment. According to the previous studies, Pd catalysts rapidly deactivates after the first run (Figure 4a) [60]. Such behaviour can be assigned to sintering and CO poisoning of NPs. Indeed, the average particle size increased from 3.0 to $4.7 \mathrm{~nm}$ during 9 hours of experiment, while carbon monoxide occupied the active sites [61,62]. The two Pd-based catalysts supported on functionalised CNFs exhibit remarkable stability up to six cycles of reaction, $12 \mathrm{~h}$ of reaction (Figure $4 \mathrm{~b}-\mathrm{c}$ ). The initial increasing in activity observed for Pd@O-HHT and Pd@P-HHT catalysts can be assigned to the desorption of PVA from the Pd NPs which blocked active sites, as previously demonstrated [63]. From XPS analysis a decrease in phosphorous and oxygen exposure in P-HHT and O-HHT after Pd deposition was detected, suggesting the preferential deposition of the metal on $\mathrm{P}$ and $\mathrm{O}$ functionalities. This result was also confirmed by STEM-EDS analysis on Pd@P-HHT catalyst, where some Pd NPs appear in contact with P (Figure 
2). This data can explain the superior durability of the functionalised catalysts thanks to the electronic interaction between Pd and functional groups. Moreover, in order to establish the selectivity of the catalysts, the gaseous products obtained were analysed after 30 minutes of reaction connecting the reactor to a microGC. The non-functionalised 1wt\%Pd@HHT showed a 55\% selectivity for the dehydrogenation pathway, while the two functionalised materials, 1wt\%Pd@O-HHT and 1wt\%Pd@P-HHT, showed an increased selectivity of $75 \%$ and $65 \%$, respectively, which remained practically constant during the six consecutive experiments, Figure 4. A reduction in the CO production for 1wt\%Pd@O-HHT and 1wt\%Pd@P-HHT can also explain the excellent stability observed for these two catalysts. Moreover, in this case HR-TEM analysis showed similar particle size before and after stability tests.
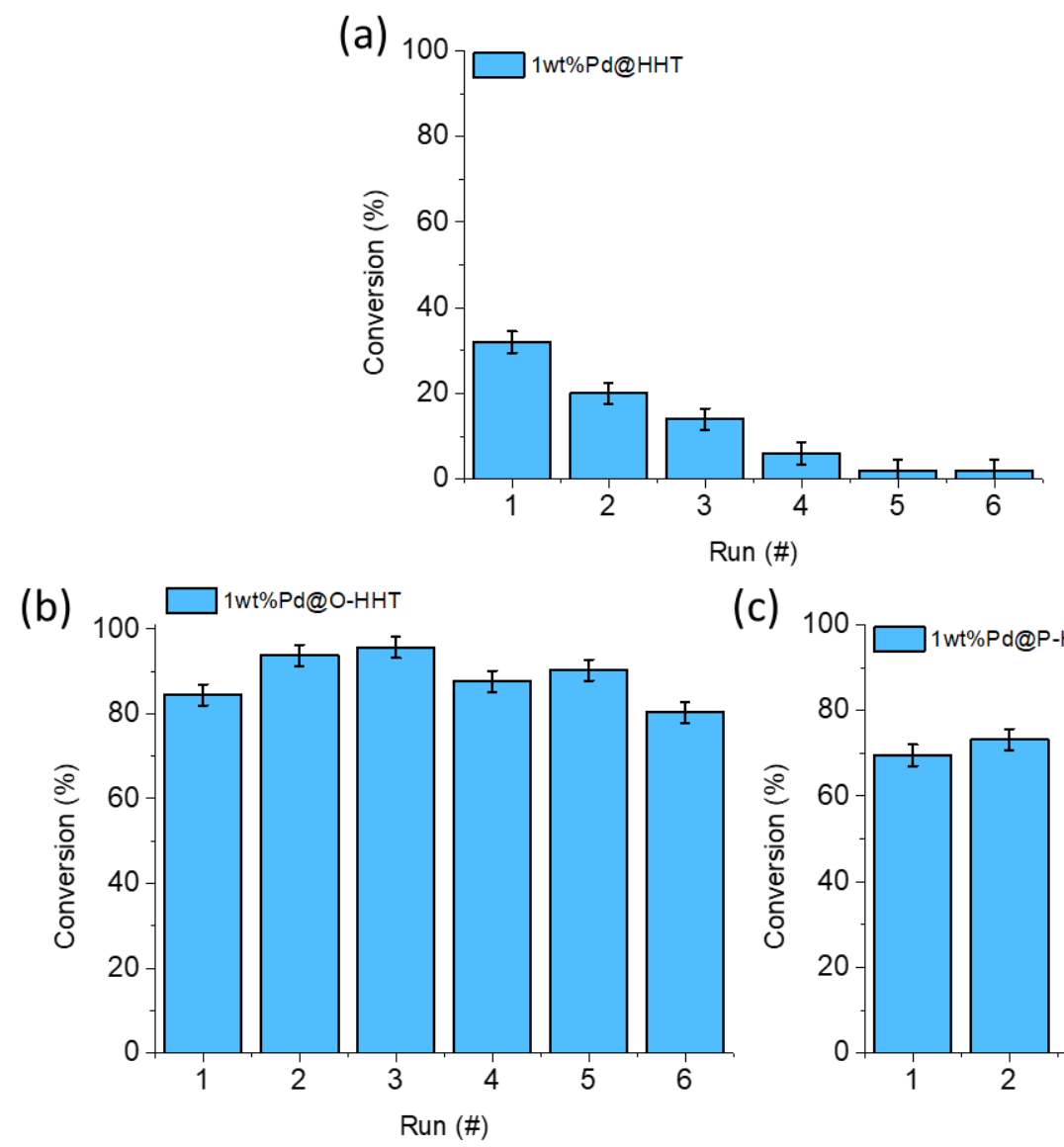

(c) 100

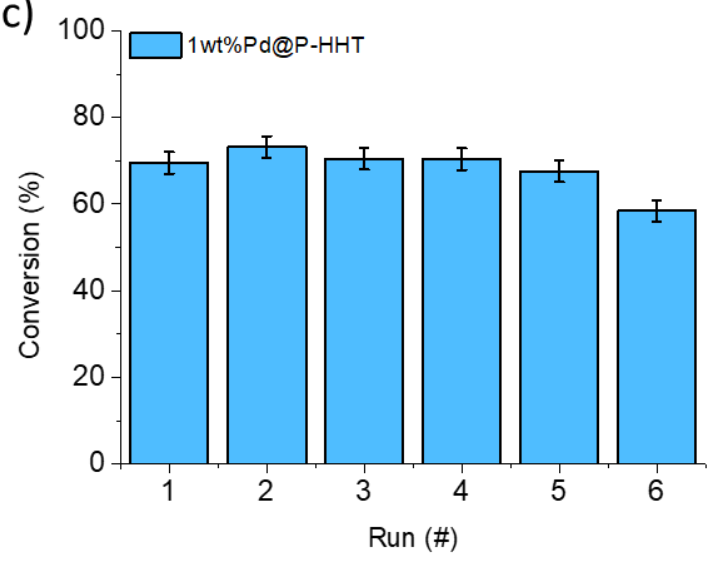

Figure 4: recycling tests of a) Pd@HHT, b) Pd@O-HHT and c) Pd@P-HHT for formic acid dehydrogenation

\subsection{DFT results}

DFT studies were performed in order to disclose the role of the different $\mathrm{O}$ and $\mathrm{P}$ functionalization on stabilising the Pd NPs. Danis demonstrated that, among all, SV is the most reactive defect towards the addition of an heteroatoms functional group[64]. Based on the typical functional groups found on the carbon 
surface after a standard functionalization procedure $[26,53,65,66]$, five different functionalization groups were anchored on the SV, i.e. carboxyl (G_COOH), hydroxyl (G_OH), carbonyl (G_CO) and phosphate $\left(\mathrm{G}_{-} \mathrm{PO}_{3} \mathrm{H}\right.$ ) groups (Figure 5).

The $\mathrm{Pd}_{15}$ cluster was brought near the defective part of the surfaces and relaxed until convergence of the interatomic forces. The optimised structures are represented in Figure 6, and different adhesion energies $\left(E_{A D H}\right)$ summarised in Table 2. For every surface, the cluster-support adhesion is negative indicating and exothermic and favourable process driven by the minimisation of cluster area[67]. All functionalised surfaces showed an $\mathrm{E}_{\mathrm{ADH}}$ between 1.649 and $0.465 \mathrm{eV}$ lower than the pristine graphene, proving an increased stability of Pd atoms upon functionalisation of the surfaces. In particular, oxygen groups displayed stronger interaction with Pd cluster, confirming the observed increased stability of the Pd@O-HHT catalyst (Figure 4b). Furthermore, the $\mathrm{E}_{\mathrm{ADH}}$ seems to be related to the catalytic activity through equation 1, excluding any $\mathrm{CO}$ poisoning through pathway 2 .

$\mathrm{FAD}_{\text {Conversion }}=\frac{\Delta \mathrm{E}_{A D H}}{E_{A D H}^{G P}} \cdot \mathrm{FAD}_{\text {Conversion }}^{\mathrm{PG}}+\mathrm{FAD}_{\text {Conversion }}^{\mathrm{PG}} \quad$ Equation 1

The $\mathrm{E}_{\mathrm{ADH}}$ of the O-functionalise catalysts is $\sim 50 \%$ lower than the one of $\mathrm{PG}$, which, added to PG relative FAD conversion (55\%), leads to a rough Pd@O-HHT conversion of 82\%. In the case of Pd@P-HHT, its $\mathrm{E}_{\mathrm{ADH}}$ is $\sim 25 \%$ lower than on PG, which relative conversion adds $14 \%$ to the PG one (55\%) resulting in $69 \%$, very close to the $65 \%$ conversion determined experimentally. The variation between the experimentally FAD conversion and the one from Equation 1 may be attributed, in principle, to CO poisoning. However, more results are needed to prove such relation and also to consider poisoning and difference in active sites.

Table 2: Adsorption energy ( $\left.E_{A D S}\right)$ of the Pd cluster on the bare and functionalised surfaces.

\begin{tabular}{c|c} 
System & $E_{A D H}(e V)$ \\
\hline$P d / P G$ & -2.029 \\
$\mathrm{Pd} / G_{C} \mathrm{COOH}$ & -3.028 \\
$\mathrm{Pd} / \mathrm{G}_{\mathrm{O}} \mathrm{OH}$ & -3.023 \\
$\mathrm{Pd} / \mathrm{G}_{-} \mathrm{CO}$ & -3.678 \\
$\mathrm{Pd} / \mathrm{G}_{-} \mathrm{PO}_{3} \mathrm{H}$ & -2.494
\end{tabular}


(a)
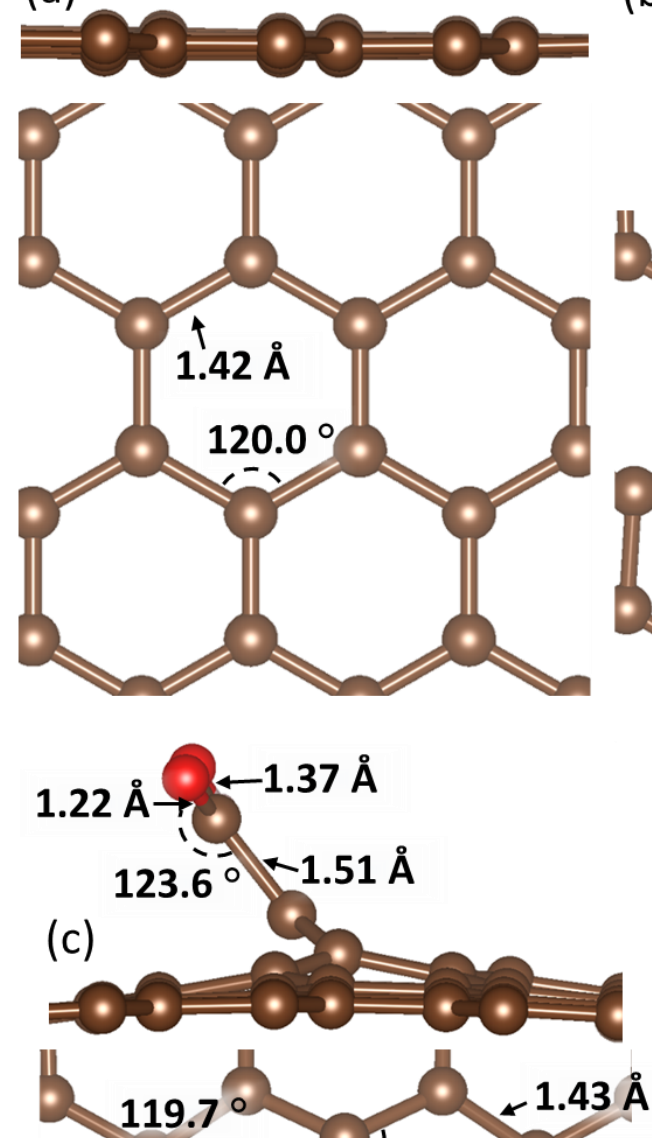

ใ $110.1 \circ 118.7^{\circ} 1.46 \AA$ 1

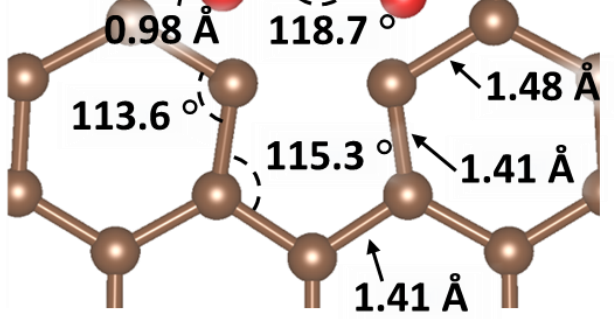

(b) $1.33 \AA$

$178.2^{\circ}-1.46 \AA$

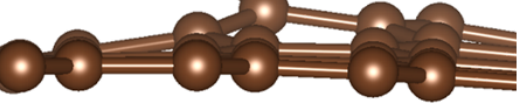

. $<1.40 \AA$

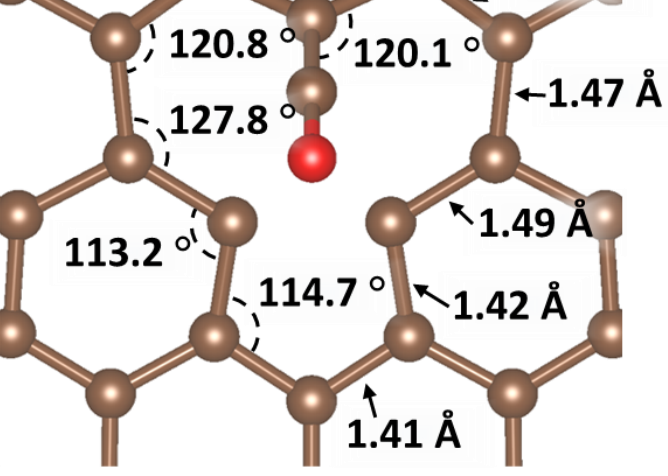

(d)

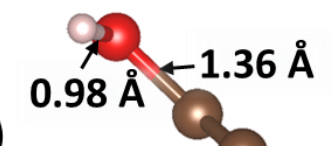

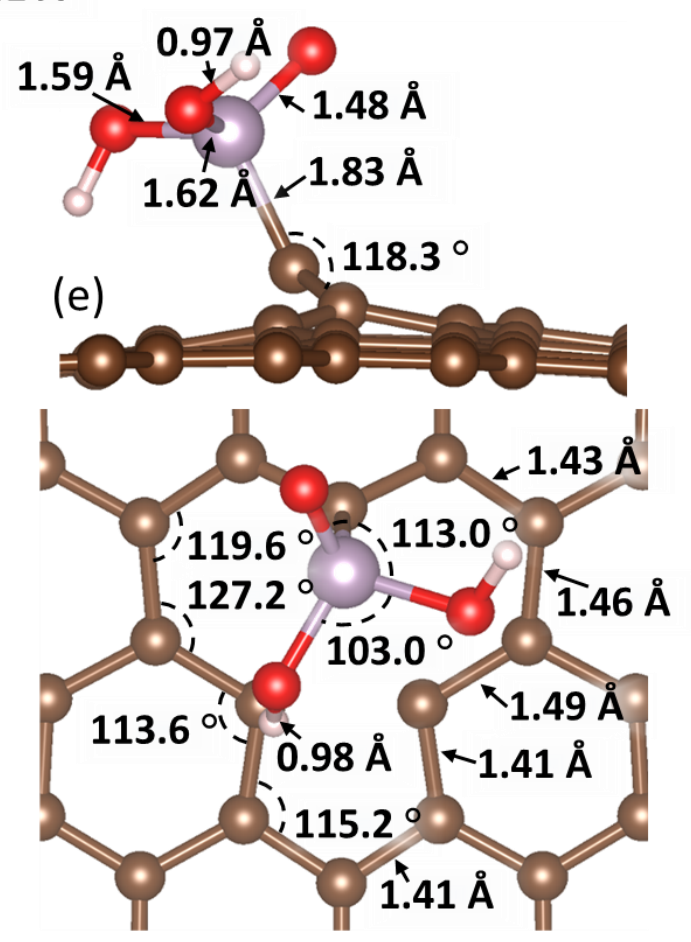


Figure 5: Side and top views of the optimized surfaces a) pristine graphene (PG), b) carbonyl doped SV graphene (G_CO), c) carboxyl doped SV graphene (G_COOH), d) hydroxyl doped SV graphene (G_OH) and e) phosphate doped SV graphene (G_PO $\left.{ }_{3} H\right)$. Inset shows the distances $(A)$ and angles $\left({ }^{\circ}\right)$ of interest. Carbon atoms are represented in brown, oxygen in red, hydrogen in white and phosphorous in violet.
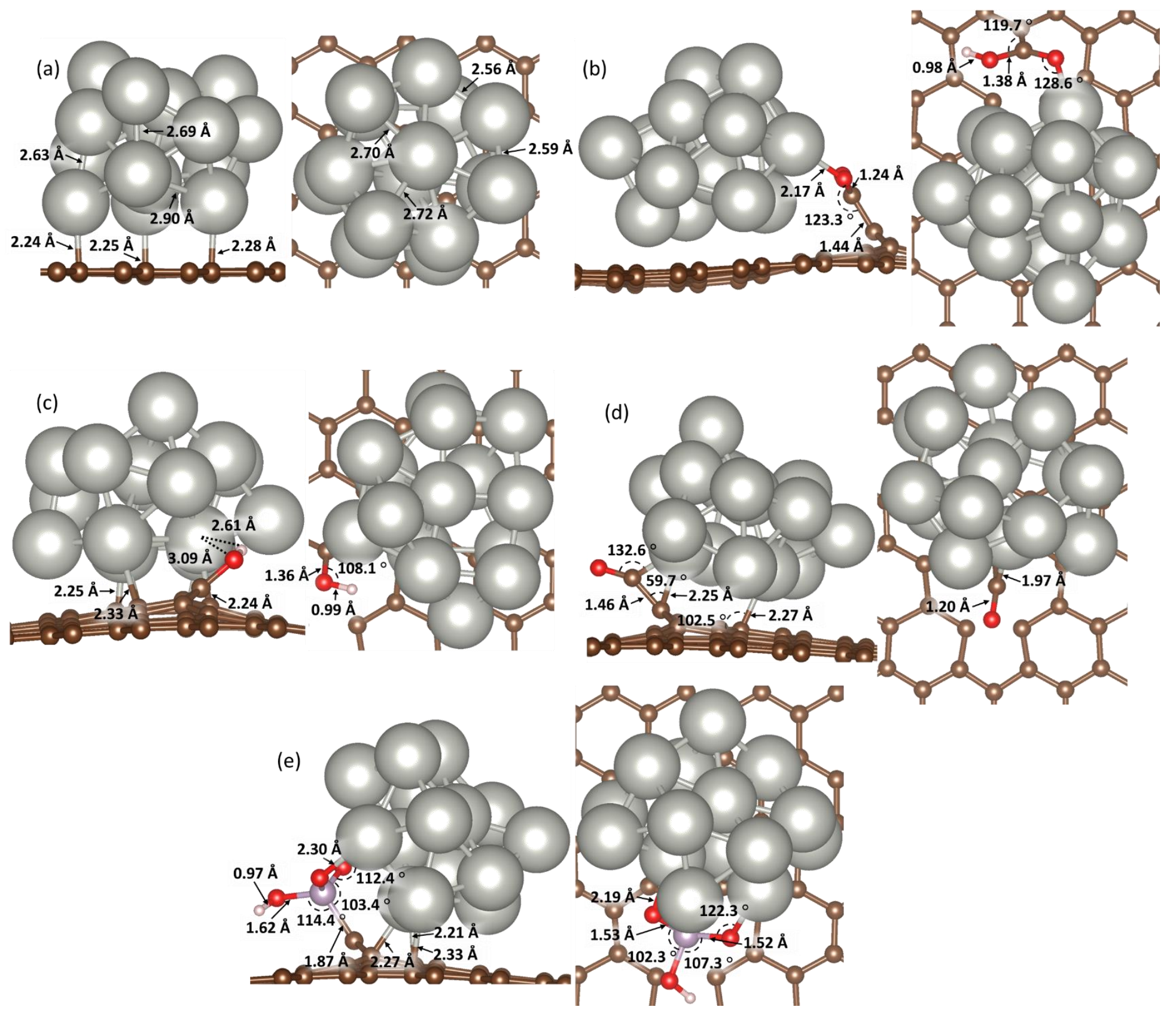

Figure 6: Side and top views of the optimized structures of $P d_{15}$ cluster on a) pristine graphene (PG), b) carboxyl doped SV graphene $\left.\left(G_{-} \mathrm{COOH}\right), c\right)$ hydroxyl doped SV graphene (G_OH), d) carbonyl doped SV graphene (G_CO) and e) phosphate doped SV graphene $\left(G_{-} P_{3} H\right)$. Inset shows the distances $(A)$ and angles $\left({ }^{\circ}\right)$ of interest. Carbon atoms are represented in brown, palladium in silver, oxygen in red, hydrogen in white and phosphorous in violet. 


\section{Conclusions:}

A combination of DFT and experimental data were employed to investigate and understand the supportmetal interaction of Pd NPs deposited on oxygen and phosphorous functionalised high-heat treated carbon nanofibers for the formic acid decomposition reaction. After the acid functionalisation of the support using $\mathrm{HNO}_{3}$ and $\mathrm{H}_{3} \mathrm{PO}_{4}$, the $\mathrm{Pd}$ particle depositions were carried out using sol-immobilization method leading to 1wt\%Pd@O-HHT and 1wt\%Pd@P-HHT catalysts. Theses catalysts obtained were characterized using TEM and XPS analyses. The kinetic profiles evidenced an increasing of conversion after two hours for both the functionalised systems respect the bare HHT standard. This enhanced catalytic behaviour can be assessed to an interaction between the metal and the functional group on the support confirmed by XPS and TEM analyses. Furthermore, an inhibition of the dehydration pathway was obtained for the functionalised materials. An excellent durability was observed in both systems during six consecutive runs, avoiding the leaching of Pd as observed for 1wt\%Pd@HHT. These results were supported by a systematic DFT study of the $\mathrm{Pd}$ adhesion energies on different $\mathrm{O}$ and $\mathrm{P}$ functionalised surfaces shedding light to the stabilisation effect of the functional groups on Pd clusters. All functionalised surfaces showed stronger stabilisation of the Pd cluster than on the pristine graphene model confirming an increased stability of Pd nanoparticles. In particular, oxygenated supports displayed a stronger interaction with Pd validating the observed increased stability of the 1wt\%Pd@O-HHT catalyst.

[1] M. Besson, P. Gallezot, C. Pinel, Conversion of biomass into chemicals over metal catalysts., Chem. Rev. 114 (2014) 1827-1870. https://doi.org/10.1021/cr4002269.

[2] T. Mallat, A. Baiker, Oxidation of Alcohols with Molecular Oxygen on Solid Catalysts, Chem. Rev. 104 (2004) 3037-3058. https://doi.org/10.1021/cr0200116.

[3] I. Favier, D. Pla, M. Gómez, Palladium Nanoparticles in Polyols: Synthesis, Catalytic Couplings, and Hydrogenations, Chem. Rev. 120 (2020) 1146-1183. https://doi.org/10.1021/acs.chemrev.9b00204.

[4] C.E. Chan-Thaw, A. Savara, A. Villa, Selective Benzyl Alcohol Oxidation over Pd Catalysts, Catal. . 8 (2018). https://doi.org/10.3390/catal8100431.

[5] W. Wu, H. Jiang, Palladium-Catalyzed Oxidation of Unsaturated Hydrocarbons Using Molecular Oxygen, Acc. Chem. Res. 45 (2012) 1736-1748. https://doi.org/10.1021/ar3000508.

[6] E. Niknam, F. Panahi, A. Khalafi-Nezhad, Immobilized Pd on a NHC functionalized metal-organic framework MIL-101(Cr): an efficient heterogeneous catalyst in Suzuki-Miyaura coupling reaction in water, Appl. Organomet. Chem. 34 (2020) e5470. https://doi.org/https://doi.org/10.1002/aoc.5470.

[7] T. Maegawa, Y. Kitamura, S. Sako, T. Udzu, A. Sakurai, A. Tanaka, Y. Kobayashi, K. Endo, U. Bora, T. 
Kurita, A. Kozaki, Y. Monguchi, H. Sajiki, Heterogeneous Pd/C-Catalyzed Ligand-Free, RoomTemperature Suzuki-Miyaura Coupling Reactions in Aqueous Media, Chem. - A Eur. J. 13 (2007) 5937-5943. https://doi.org/https://doi.org/10.1002/chem.200601795.

[8] A. Villa, N. Dimitratos, C.E. Chan-Thaw, C. Hammond, L. Prati, G.J. Hutchings, Glycerol Oxidation Using Gold-Containing Catalysts, Acc. Chem. Res. 48 (2015) 1403-1412. https://doi.org/10.1021/ar500426g.

[9] J.J. Liu, Advanced Electron Microscopy of Metal-Support Interactions in Supported Metal Catalysts, ChemCatChem. 3 (2011) 934-948. https://doi.org/10.1002/cctc.201100090.

[10] S.B. Simonsen, I. Chorkendorff, S. Dahl, M. Skoglundh, J. Sehested, S. Helveg, Direct Observations of Oxygen-induced Platinum Nanoparticle Ripening Studied by In Situ TEM, J. Am. Chem. Soc. 132 (2010) 7968-7975. https://doi.org/10.1021/ja910094r.

[11] S.R. Challa, A.T. Delariva, T.W. Hansen, S. Helveg, J. Sehested, P.L. Hansen, F. Garzon, A.K. Datye, Relating Rates of Catalyst Sintering to the Disappearance of Individual Nanoparticles during Ostwald Ripening, J. Am. Chem. Soc. 133 (2011) 20672-20675. https://doi.org/10.1021/ja208324n.

[12] X. Wang, G. Sun, P. Routh, D.-H. Kim, W. Huang, P. Chen, Heteroatom-doped graphene materials: syntheses, properties and applications, Chem. Soc. Rev. 43 (2014) 7067-7098. https://doi.org/10.1039/C4CS00141A.

[13] A.A.-N. Mohammad Saleh Shafeeyan, Wan Mohd Ashri Wan Daud, Amirhossein Houshmand, Ammonia modification of activated carbon to enhance carbon dioxide adsorption: Effect of preoxidation, Appl. Surf. Sci. 257 (2011) 3936-3942. https://doi.org/10.1016/j.apsusc.2010.11.127.

[14] M.S. Shafeeyan, W.M.A.W. Daud, A. Houshmand, A. Shamiri, A review on surface modification of activated carbon for carbon dioxide adsorption, J. Anal. Appl. Pyrolysis. 89 (2010) 143-151. https://doi.org/10.1016/j.jaap.2010.07.006.

[15] W.M.A.W. Daud, A.H. Houshamnd, Textural characteristics, surface chemistry and oxidation of activated carbon, J. Nat. Gas Chem. 19 (2010) 267-279. https://doi.org/10.1016/S10039953(09)60066-9.

[16] S. Sarioglan, Recovery of Palladium from Spent Catalysts, Platinummetalsreview. 57 (2013) 289-296.

[17] P. Hu, Z. Huang, Z. Amghouz, M. Makkee, F. Xu, F. Kapteijn, A. Dikhtiarenko, Y. Chen, X. Gu, X. Tang, Electronic Metal-Support Interactions in Single-Atom Catalysts, Angew. Chemie Int. Ed. 53 (2014) 3418-3421. https://doi.org/https://doi.org/10.1002/anie.201309248. 
[18] R. Arrigo, M.E. Schuster, Z. Xie, Y. Yi, G. Wowsnick, L.L. Sun, K.E. Hermann, M. Friedrich, P. Kast, M. Hävecker, A. Knop-Gericke, R. Schlögl, Nature of the N-Pd Interaction in Nitrogen-Doped Carbon Nanotube Catalysts, ACS Catal. 5 (2015) 2740-2753. https://doi.org/10.1021/acscatal.5b00094.

[19] B. Zhang, L. Shao, W. Zhang, X. Sun, X. Pan, D.S. Su, Interaction between palladium nanoparticles and surface-modified carbon nanotubes: Role of surface functionalities, ChemCatChem. 6 (2014) 2607-2612. https://doi.org/10.1002/cctc.201402272.

[20] T.-J. Zhao, D. Chen, Y.-C. Dai, W.-K. Yuan, A. Holmen, The effect of graphitic platelet orientation on the properties of carbon nanofiber supported Pd catalysts prepared by ion exchange, Top. Catal. 45 (2007) 87-91. https://doi.org/10.1007/s11244-007-0245-4.

[21] I. Efremenko, M. Sheintuch, Carbon-supported palladium catalysts. Molecular orbital study, J. Catal. 214 (2003) 53-67. https://doi.org/https://doi.org/10.1016/S0021-9517(02)00103-3.

[22] X. Wang, N. Li, J.A. Webb, L.D. Pfefferle, G.L. Haller, Effect of surface oxygen containing groups on the catalytic activity of multi-walled carbon nanotube supported Pt catalyst, Appl. Catal. B Environ. 101 (2010) 21-30. https://doi.org/https://doi.org/10.1016/j.apcatb.2010.08.028.

[23] G.-H. Wang, Z. Cao, D. Gu, N. Pfänder, A.-C. Swertz, B. Spliethoff, H.-J. Bongard, C. Weidenthaler, W. Schmidt, R. Rinaldi, F. Schüth, Nitrogen-Doped Ordered Mesoporous Carbon Supported Bimetallic PtCo Nanoparticles for Upgrading of Biophenolics, Angew. Chemie Int. Ed. 55 (2016) 8850-8855. https://doi.org/https://doi.org/10.1002/anie.201511558.

[24] Q. Li, S. Zhang, L. Dai, L. Li, Nitrogen-Doped Colloidal Graphene Quantum Dots and Their SizeDependent Electrocatalytic Activity for the Oxygen Reduction Reaction, J. Am. Chem. Soc. 134 (2012) 18932-18935. https://doi.org/10.1021/ja309270h.

[25] A. Kubacka, B. Bachiller-Baeza, G. Colón, M. Fernández-García, Doping level effect on sunlight-driven W,N-co-doped TiO2-anatase photo-catalysts for aromatic hydrocarbon partial oxidation, Appl. Catal. B Environ. 93 (2010) 274-281. https://doi.org/https://doi.org/10.1016/j.apcatb.2009.09.039.

[26] S. Campisi, S. Capelli, D. Motta, F. Trujillo, T. Davies, L. Prati, N. Dimitratos, A. Villa, Catalytic Performances of Au-Pt Nanoparticles on Phosphorous Functionalized Carbon Nanofibers towards HMF Oxidation, C. 4 (2018) 48. https://doi.org/10.3390/c4030048.

[27] M. Terrones, A. Jorio, M. Endo, A.M. Rao, Y.A. Kim, T. Hayashi, H. Terrones, J.-C. Charlier, G. Dresselhaus, M.S. Dresselhaus, New direction in nanotube science, Mater. Today. 7 (2004) 30-45. https://doi.org/https://doi.org/10.1016/S1369-7021(04)00447-X. 
[28] S. Latil, S. Roche, D. Mayou, J.-C. Charlier, Mesoscopic Transport in Chemically Doped Carbon Nanotubes, Phys. Rev. Lett. 92 (2004) 256805. https://doi.org/10.1103/PhysRevLett.92.256805.

[29] D.A. Bulushev, M. Zacharska, E. V. Shlyakhova, A.L. Chuvilin, Y. Guo, S. Beloshapkin, A. V. Okotrub, L.G. Bulusheva, Single Isolated Pd2+ Cations Supported on N-Doped Carbon as Active Sites for Hydrogen Production from Formic Acid Decomposition, ACS Catal. 6 (2016) 681-691. https://doi.org/10.1021/acscatal.5b02381.

[30] Z. Li, X. Yang, N. Tsumori, Z. Liu, Y. Himeda, T. Autrey, Q. Xu, Tandem Nitrogen Functionalization of Porous Carbon: Toward Immobilizing Highly Active Palladium Nanoclusters for Dehydrogenation of Formic Acid, ACS Catal. 7 (2017) 2720-2724. https://doi.org/10.1021/acscatal.7b00053.

[31] S. Masuda, K. Mori, Y. Futamura, H. Yamashita, PdAg Nanoparticles Supported on Functionalized Mesoporous Carbon: Promotional Effect of Surface Amine Groups in Reversible Hydrogen Delivery/Storage Mediated by Formic Acid/CO2, ACS Catal. 8 (2018) 2277-2285. https://doi.org/10.1021/acscatal.7b04099.

[32] S. Zhong, N. Tsumori, M. Kitta, Q. Xu, Immobilizing palladium nanoparticles on boron-oxygenfunctionalized carbon nanospheres towards efficient hydrogen generation from formic acid, Nano Res. 12 (2019) 2966-2970. https://doi.org/10.1007/s12274-019-2539-9.

[33] Z. Xin, S. Wang, J. Wang, X. Huang, X. Ji, Y. Yao, L. Shao, Nanosizing low-loading Pd on phosphorusdoped carbon nanotubes for enhanced $\mathrm{HCOOH}$ oxidation performance, Electrochem. Commun. 67 (2016) 26-30. https://doi.org/10.1016/j.elecom.2016.03.008.

[34] W. Guo, S. Niu, X. Ji, W. Yu, T.-W. Lin, Y. Wu, Y. Li, L. Shao, Doping carbon networks with phosphorus for supporting Pd in catalyzing selective oxidation of benzyl alcohol, J. Nanoparticle Res. 20 (2018) 180. https://doi.org/10.1007/s11051-018-4279-2.

[35] F. Joó, Breakthroughs in hydrogen storage-formic acid as a sustainable storage material for hydrogen, ChemSusChem. 1 (2008) 805-808. https://doi.org/10.1002/cssc.200800133.

[36] A.K. Singh, S. Singh, A. Kumar, Hydrogen energy future with formic acid: A renewable chemical hydrogen storage system, Catal. Sci. Technol. 6 (2016) 12-40. https://doi.org/10.1039/c5cy01276g.

[37] Z. Zhang, L. Zhang, M.J. Hülsey, N. Yan, Zirconia phase effect in Pd/ZrO2 catalyzed CO2 hydrogenation into formate, Mol. Catal. 475 (2019) 110461.

[38] M. Grasemann, G. Laurenczy, Formic acid as a hydrogen source - Recent developments and future trends, Energy Environ. Sci. 5 (2012) 8171-8181. https://doi.org/10.1039/c2ee21928j. 
[39] S. Campisi, D. Ferri, A. Villa, W. Wang, D. Wang, O. Kröcher, L. Prati, Selectivity Control in PalladiumCatalyzed Alcohol Oxidation through Selective Blocking of Active Sites, J. Phys. Chem. C. 120 (2016) 14027-14033. https://doi.org/10.1021/acs.jpcc.6b01549.

[40] F. Sanchez, M.H. Alotaibi, D. Motta, C.E. Chan-Thaw, A. Rakotomahevitra, T. Tabanelli, A. Roldan, C. Hammond, Q. He, T. Davies, A. Villa, N. Dimitratos, Hydrogen production from formic acid decomposition in the liquid phase using Pd nanoparticles supported on CNFs with different surface properties, Sustain. Energy Fuels. 2 (2018) 2705-2716. https://doi.org/10.1039/c8se00338f.

[41] G. Kresse, J. Furthmüller, Efficiency of ab-initio total energy calculations for metals and semiconductors using a plane-wave basis set, Comput. Mater. Sci. 6 (1996) 15-50. https://doi.org/https://doi.org/10.1016/0927-0256(96)00008-0.

[42] T. Bučko, J. Hafner, S. Lebègue, J.G. Ángyán, Improved Description of the Structure of Molecular and Layered Crystals: Ab Initio DFT Calculations with van der Waals Corrections, J. Phys. Chem. A. 114 (2010) 11814-11824. https://doi.org/10.1021/jp106469x.

[43] B. Hammer, L.B. Hansen, J.K. Nørskov, Improved adsorption energetics within density-functional theory using revised Perdew-Burke-Ernzerhof functionals, Phys. Rev. B. 59 (1999) 7413-7421. https://doi.org/10.1103/PhysRevB.59.7413.

[44] J.P. Perdew, K. Burke, M. Ernzerhof, Generalized Gradient Approximation Made Simple, Phys. Rev. Lett. 77 (1996) 3865-3868. https://doi.org/10.1103/PhysRevLett.77.3865.

[45] G. Kresse, D. Joubert, From ultrasoft pseudopotentials to the projector augmented-wave method, Phys. Rev. B. 59 (1999) 1758-1775. https://doi.org/10.1103/PhysRevB.59.1758.

[46] P.E. Blöchl, O. Jepsen, O.K. Andersen, Improved tetrahedron method for Brillouin-zone integrations, Phys. Rev. B. 49 (1994) 16223-16233. https://doi.org/10.1103/PhysRevB.49.16223.

[47] S. Grimme, S. Ehrlich, L. Goerigk, Effect of the damping function in dispersion corrected density functional theory, J. Comput. Chem. 32 (2011) 1456-1465. https://doi.org/https://doi.org/10.1002/jcc.21759.

[48] K. Mathew, V.S.C. Kolluru, S. Mula, S.N. Steinmann, R.G. Hennig, Implicit self-consistent electrolyte model in plane-wave density-functional theory, J. Chem. Phys. 151 (2019) 234101. https://doi.org/10.1063/1.5132354.

[49] K. Mathew, R. Sundararaman, K. Letchworth-Weaver, T.A. Arias, R.G. Hennig, Implicit solvation model for density-functional study of nanocrystal surfaces and reaction pathways, J. Chem. Phys. 
140 (2014). https://doi.org/10.1063/1.4865107.

[50] A.K. Geim, Graphene: Status and Prospects, Science (80-. ). 324 (2009) 1530 LP - 1534. https://doi.org/10.1126/science.1158877.

[51] R.L. Johnston, Evolving better nanoparticles: Genetic algorithms for optimising cluster geometries, Dalt. Trans. (2003) 4193-4207. https://doi.org/10.1039/B305686D.

[52] G. Sun, J.T. Fuller, A.N. Alexandrova, P. Sautet, Global Activity Search Uncovers Reaction Induced Concomitant Catalyst Restructuring for Alkane Dissociation on Model Pt Catalysts, ACS Catal. 11 (2021) 1877-1885. https://doi.org/10.1021/acscatal.0c05421.

[53] X. Wu, L.R. Radovic, Inhibition of catalytic oxidation of carbon/carbon composites by phosphorus, Carbon N. Y. 44 (2006) 141-151. https://doi.org/https://doi.org/10.1016/j.carbon.2005.06.038.

[54] S. Campisi, F. Sanchez Trujillo, D. Motta, T. Davies, N. Dimitratos, A. Villa, Controlling the Incorporation of Phosphorus Functionalities on Carbon Nanofibers: Effects on the Catalytic Performance of Fructose Dehydration, C. 4 (2018) 9. https://doi.org/10.3390/c4010009.

[55] I. Barlocco, S. Capelli, E. Zanella, X. Chen, J.J. Delgado, A. Roldan, N. Dimitratos, A. Villa, Synthesis of palladium-rhodium bimetallic nanoparticles for formic acid dehydrogenation, J. Energy Chem. 52 (2020) 301-309. https://doi.org/10.1016/j.jechem.2020.04.031.

[56] F. Sanchez, M.H. Alotaibi, D. Motta, C.E. Chan-Thaw, A. Rakotomahevitra, T. Tabanelli, A. Roldan, C. Hammond, Q. He, T. Davies, A. Villa, N. Dimitratos, Hydrogen production from formic acid decomposition in the liquid phase using Pd nanoparticles supported on CNFs with different surface properties, Sustain. Energy Fuels. 2 (2018) 2705-2716. https://doi.org/10.1039/c8se00338f.

[57] A. Villa, D. Wang, C.E. Chan-Thaw, S. Campisi, G.M. Veith, L. Prati, The confinement effect on the activity of Au NPs in polyol oxidation, Catal. Sci. Technol. 6 (2016) 598-601. https://doi.org/10.1039/c5cy01593f.

[58] J. Bedia, J.M. Rosas, J. Márquez, J. Rodríguez-Mirasol, T. Cordero, Preparation and characterization of carbon based acid catalysts for the dehydration of 2-propanol, Carbon N. Y. 47 (2009) 286-294. https://doi.org/https://doi.org/10.1016/j.carbon.2008.10.008.

[59] S. Kundu, Y. Wang, W. Xia, M. Muhler, Thermal Stability and Reducibility of Oxygen-Containing Functional Groups on Multiwalled Carbon Nanotube Surfaces: A Quantitative High-Resolution XPS and TPD/TPR Study, J. Phys. Chem. C. 112 (2008) 16869-16878. https://doi.org/10.1021/jp804413a.

[60] F. Sanchez, D. Motta, A. Roldan, C. Hammond, A. Villa, N. Dimitratos, Hydrogen Generation from 
Additive-Free Formic Acid Decomposition Under Mild Conditions by Pd/C: Experimental and DFT Studies, Top. Catal. 61 (2018) 254-266. https://doi.org/10.1007/s11244-018-0894-5.

[61] F. Abild-Pedersen, M.P. Andersson, $\mathrm{CO}$ adsorption energies on metals with correction for high coordination adsorption sites - A density functional study, Surf. Sci. 601 (2007) 1747-1753. https://doi.org/10.1016/j.susc.2007.01.052.

[62] H. Sakai, T. Nakajima, N. Yoshida, S. Kishimoto, Poisoning effect of carbon monoxide on the desorption process of hydrogen from palladium, React. Kinet. Catal. Lett. 19 (1982) 297-301. https://doi.org/10.1007/BF02074049.

[63] S. Campisi, C.E. Chan-Thaw, D. Wang, A. Villa, L. Prati, Metal nanoparticles on carbon based supports: The effect of the protective agent removal, Catal. Today. 278 (2016) 91-96. https://doi.org/https://doi.org/10.1016/j.cattod.2016.04.026.

[64] P.A. Denis, F. Iribarne, Comparative Study of Defect Reactivity in Graphene, J. Phys. Chem. C. 117 (2013) 19048-19055. https://doi.org/10.1021/jp4061945.

[65] I. Barlocco, S. Capelli, X. Lu, S. Tumiati, N. Dimitratos, A. Roldan, A. Villa, Role of defects in carbon materials during metal-free formic acid dehydrogenation, Nanoscale. (2020) 22768-22777. https://doi.org/10.1039/d0nr05774f.

[66] R. Arrigo, M. Hävecker, S. Wrabetz, R. Blume, M. Lerch, J. McGregor, E.P.J. Parrott, J.A. Zeitler, L.F. Gladden, A. Knop-Gericke, R. Schlögl, D.S. Su, Tuning the acid/base properties of nanocarbons by functionalization via amination, J. Am. Chem. Soc. 132 (2010) 9616-9630. https://doi.org/10.1021/ja910169v.

[67] L. Ratke, P.W. Voorhees, Growth and Coarsening : Ostwald Ripening in Material Processing, Springer Berlin Heidelberg, 2002. https://www.springer.com/gp/book/9783540425632. 
SUPPLEMENTARY INFORMATION

ENHANCING ACTIVITY, SELECTIVITY AND STABILITY OF PALLADIUM CATALYSTS IN FORMIC ACID DECOMPOSITION: EFFECT OF SUPPORT FUNCTIONALIZATION

Ilaria Barlocco, ${ }^{a}$ Silvio Bellomi, ${ }^{a}$ Juan J. Delgado, ${ }^{b}$ Xiaowei Chen, ${ }^{b}$ Laura Prati, ${ }^{a}$ Nikolaos Dimitratos, ${ }^{c}$ Alberto Roldan, ${ }^{d}$ Alberto Villa ${ }^{a, *}$

${ }^{a}$ Dipartimento di Chimica, Università degli Studi di Milano, via Golgi 19, I-20133Milano, Italy

${ }^{\mathrm{b}}$ Departamento de Ciencia de los Materiales, Ingeniería Metalúrgica y Química Inorgánica, Facultad de Ciencias, Universidad de Cádiz, Campus Río San Pedro, Puerto Real (Cádiz), E-11510, Spain

${ }^{c}$ Dipartimento di Chimica Industriale e dei Materiali, ALMA MATER STUDIORUM Università di Bologna, Viale Risorgimento 4, 40136 Bologna, Italy

${ }^{\mathrm{d}}$ Cardiff Catalysis Institute, School of Chemistry, Cardiff University, Main Building, Park Place, CF10 3AT, Cardiff, United Kingdom

*Corresponding author

E-mail addresses: Alberto.Villa@unimi.it (A. Villa)

The present supplementary information contains in Figures S1 and S2 the high-resolution spectra of Pd3d and O1s, respectively. Figure S3 presents the STEM-EDS element mapping analysis of sample 1\%Pd@P-HHT. Table S1 shows a comparison of the activity of different Pd-based catalysts with the materials presented in this work. 

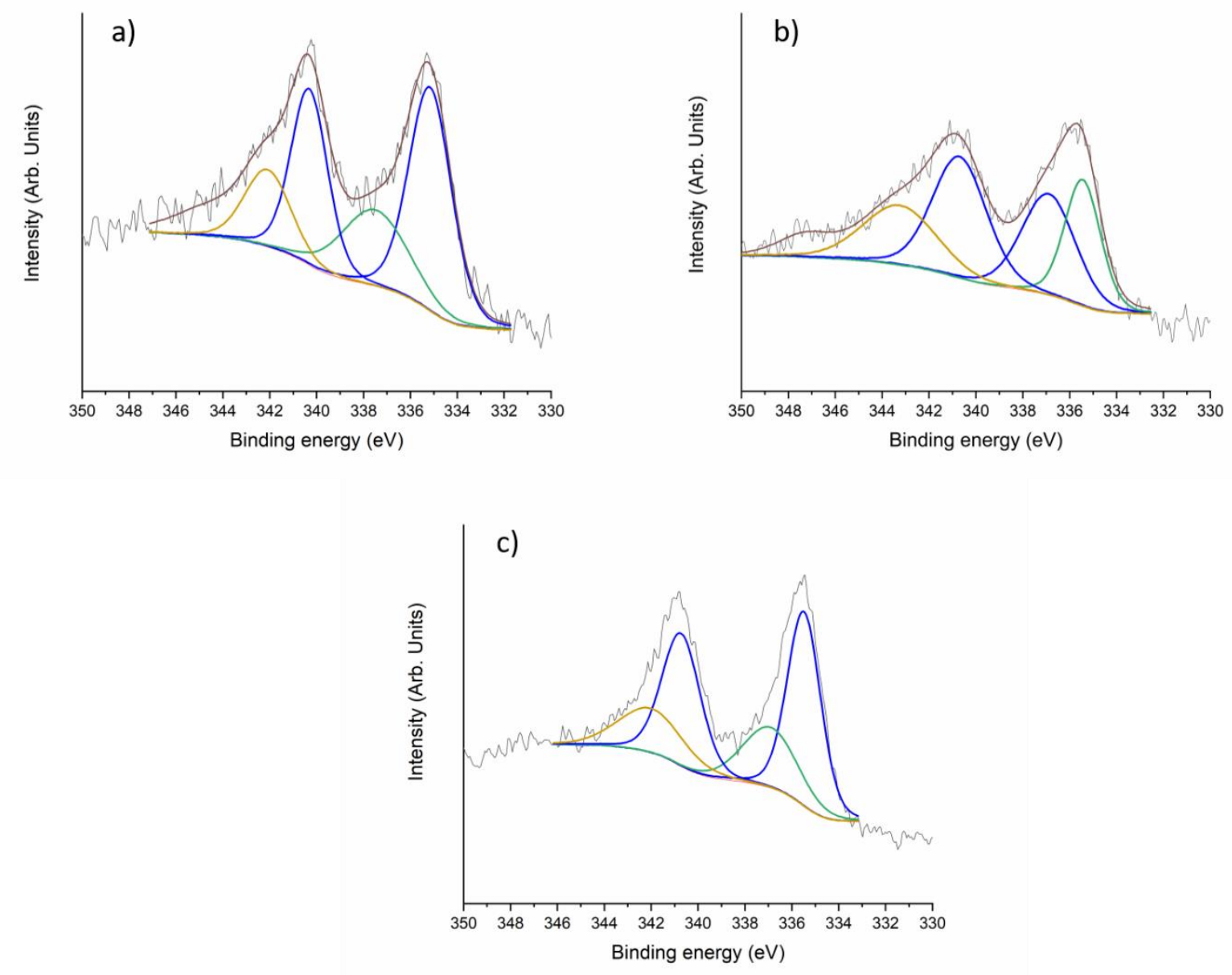

Figure S1: XPS Pd 3d spectra for a) Pd-HHT, b) Pd@O-HHT and c) Pd@P-HHT 

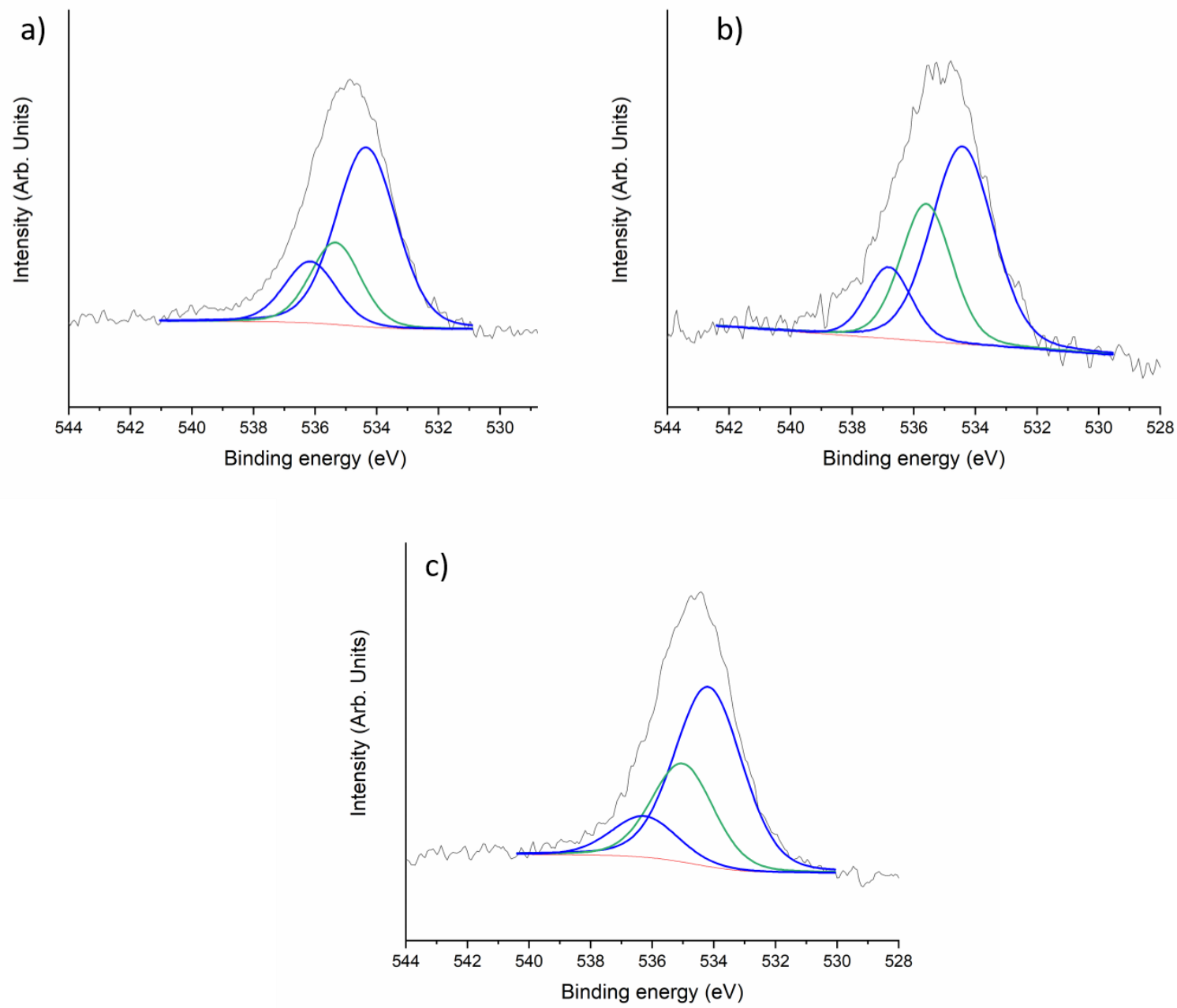

Figure S2: XPS O1s spectra for a) Pd-HHT, b) Pd@O-HHT and c) Pd@P-HHT 


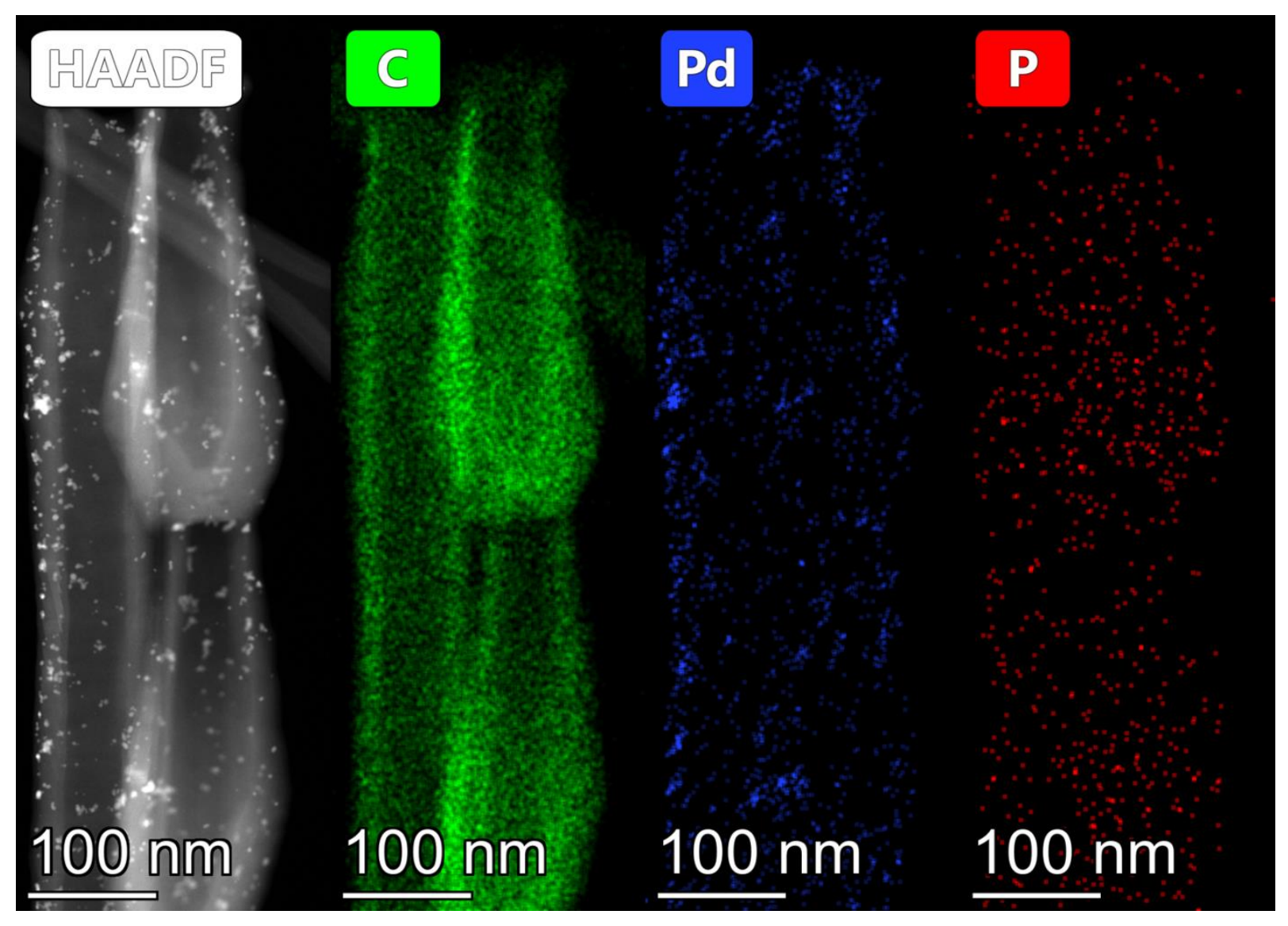

Figure S3: STEM-EDS element mapping analysis of sample 1\%Pd@P-HHT. 


\begin{tabular}{|c|c|c|c|c|}
\hline Catalyst & $\mathrm{T}(\mathrm{O} C)$ & Reagent & $\begin{array}{l}\text { Initial } \\
\text { Activity } \\
\left(\mathbf{h}^{-1}\right)\end{array}$ & Ref. \\
\hline Pd@P-HHT & 30 & Formic acid $(0.5 \mathrm{M})$ & 899 & This work \\
\hline Pd@O-HHT & 30 & Formic acid $(0.5 \mathrm{M})$ & 1485 & This work \\
\hline $\mathrm{Pd} / \mathrm{HHT}$ & 30 & Formic acid $(0.5 \mathrm{M})$ & 979 & {$[1]$} \\
\hline $\mathrm{Pd}-\mathrm{MnO}_{\mathrm{x}} / \mathrm{SiO}_{2}-\mathrm{NH}_{2}$ & 20 & Formic acid (0.265 M) & 140 & {$[2]$} \\
\hline Pd/rGO-AP & 50 & Formic Acid (10 M) & 477 & [3] \\
\hline Pd@SBA-15/DTC & 25 & Formic acid (2.0 M) & 1952 & [4] \\
\hline $\mathrm{Pd} /$ resin & 75 & $\mathrm{HCOOH} / \mathrm{HCOONa}=9 / 1$ & 820 & {$[5]$} \\
\hline $\mathrm{Pd}-\mathrm{MnO}_{\mathrm{x}} / \mathrm{NH}_{2}-\mathrm{KIE}-6$ & 25 & Formic Acid (0.5 M) & 541 & [6] \\
\hline $\begin{array}{l}\mathrm{Pd}(2 \mathrm{wt} \%)-\mathrm{MnOx}(\mathrm{Mn} \\
\text { basis } 4 \mathrm{wt} \%) / \mathrm{NH}_{2}-\mathrm{KIE6}-\mathrm{C}\end{array}$ & 25 & Formic Acid (0.5 M) & 593 & [7] \\
\hline Pd/NMC-400 & 25 & Formic Acid (1 M) & 913 & [8] \\
\hline Pd/NMC-500 & 25 & Formic Acid (1 M) & 680 & [8] \\
\hline Pd/NMC-600 & 25 & Formic Acid (1 M) & 642 & [8] \\
\hline Pd/NMC-700 & 25 & Formic Acid (1 M) & 469 & [8] \\
\hline $5 \mathrm{wt} \% \mathrm{Pd} / \mathrm{C}$ & 30 & Formic Acid (0.5 M) & 1136 & [9] \\
\hline
\end{tabular}

[1] F. Sanchez, M.H. Alotaibi, D. Motta, C.E. Chan-Thaw, A. Rakotomahevitra, T. Tabanelli, A. Roldan, C. Hammond, Q. He, T. Davies, A. Villa, N. Dimitratos, Hydrogen production from formic acid decomposition in the liquid phase using Pd nanoparticles supported on CNFs with different surface properties, Sustain. Energy Fuels. 2 (2018) 2705-2716. https://doi.org/10.1039/c8se00338f.

[2] A. Bulut, M. Yurderi, Y. Karatas, M. Zahmakiran, H. Kivrak, M. Gulcan, M. Kaya, Pd-MnOx nanoparticles dispersed on amine-grafted silica: Highly efficient nanocatalyst for hydrogen production from additive-free dehydrogenation of formic acid under mild conditions, Appl. Catal. B Environ. 164 (2015) 324-333. https://doi.org/https://doi.org/10.1016/j.apcatb.2014.09.041.

[3] S.S. Biswas, M.S. Tandrapadu, E. Abinaya, M. Eswaramoorthy, Deciphering the role of amine in amino silane-functionalized $\mathrm{Pd} / \mathrm{rGO}$ catalyst for formic acid decomposition at room temperature, Bull. Mater. Sci. 43 (2020) 1-6.

[4] M. Farajzadeh, H. Alamgholiloo, F. Nasibipour, R. Banaei, S. Rostamnia, Anchoring Pd-nanoparticles on dithiocarbamate-functionalized SBA-15 for hydrogen generation from formic acid, Sci. Rep. 10 (2020) 1-9. 
[5] K. Mori, M. Dojo, H. Yamashita, Pd and Pd-Ag Nanoparticles within a Macroreticular Basic Resin: An Efficient Catalyst for Hydrogen Production from Formic Acid Decomposition, ACS Catal. 3 (2013) 1114-1119. https://doi.org/10.1021/cs400148n.

[6] D.-W. Lee, M.-H. Jin, J.C. Park, C.-B. Lee, D. Oh, S.-W. Lee, J.-W. Park, J.-S. Park, Waste-GlycerolDirected Synthesis of Mesoporous Silica and Carbon with Superior Performance in RoomTemperature Hydrogen Production from Formic Acid, Sci. Rep. 5 (2015) 15931. https://doi.org/10.1038/srep15931.

[7] M.-H. Jin, D. Oh, J.-H. Park, C.-B. Lee, S.-W. Lee, J.-S. Park, K.-Y. Lee, D.-W. Lee, Mesoporous Silica Supported Pd-MnOx Catalysts with Excellent Catalytic Activity in Room-Temperature Formic Acid Decomposition, Sci. Rep. 6 (2016) 33502. https://doi.org/10.1038/srep33502.

[8] J. Sun, H. Qiu, W. Cao, H. Fu, H. Wan, Z. Xu, S. Zheng, Ultrafine Pd Particles Embedded in NitrogenEnriched Mesoporous Carbon for Efficient H2 Production from Formic Acid Decomposition, ACS Sustain. Chem. Eng. 7 (2019) 1963-1972. https://doi.org/10.1021/acssuschemeng.8b04130.

[9] F. Sanchez, D. Motta, A. Roldan, C. Hammond, A. Villa, N. Dimitratos, Hydrogen Generation from Additive-Free Formic Acid Decomposition Under Mild Conditions by Pd/C: Experimental and DFT Studies, Top. Catal. 61 (2018) 254-266. https://doi.org/10.1007/s11244-018-0894-5. 